\title{
PRODUÇÃO, CARACTERIZAÇÃO E AVALIAÇÃO SENSORIAL DE FERMENTADO DE Syzygium cuminiL. (BRINCO DE VIÚVA).
}

\author{
SANTOS, A.M.Jr. ${ }^{1}$, SILVA, J.R.A.S. ${ }^{1}$, SILVA, M.C.S. ${ }^{1}$, VIEIRA, R.C. ${ }^{1}$, ALMEIDA, \\ R.M.R.G. ${ }^{1}$
}

1.Universidade Federal de Alagoas, Centro de Tecnologia

E-mail para contato: aldosantos89@gmail.com

\begin{abstract}
RESUMO - O brinco de viúva (Syzygium cumini L.) pertence à família Mirtaceae, que inclui também espécies de outras frutas tropicais do Brasil como a goiaba e a pitanga. É uma planta bastante conhecida na medicina popular, seu suco é utilizado como adstringente e diurético, e por possuir compostos antioxidantes, torna-se bastante útil no combate de algumas patologias como o câncer. Este trabalho teve como objetivo, produção, caracterização e avaliação sensorial do fermentado de brinco de viúva. O suco foi extraído e foram realizadas analises físico-químicas com o suco da fruta tais como: sólidos solúveis e totais, acidez, $\mathrm{pH}$, acido ascórbico e açúcares redutores. O suco da fruta sofreu uma fermentação etanólica com fermento comercial, e a fermentação foi acompanhada por vários dias através do Brix e do teor alcoólico. O vinho foi caracterizado físicoquímicamente e avaliado sensorialmente quanto à aceitabilidade e também quanto à frequência de consumo por provadores não treinados. O produto mostrou-se adequado, com índice de aceitação acima de $75 \%$ considerado aceitável pelos provadores.
\end{abstract}

\section{INTRODUÇÃO}

O Brasil é terceiro maior produtor mundial de frutas, algo em torno de 44 milhões de toneladas no ano de 2013 (CNA, 2013), perdendo apenas para China e Índia. Dentre inúmeras frutas, produzidas no país, o brinco de viúva é obtido de uma arvore pertencente à família Myrtaceae, botanicamente classificada como Eugenia jambola, e posteriormente reclassificada como Syzygium cumini (Lago et al, 2006). É conhecida popularmente como jambolão, jamelão, cereja, jalão, kambol, jambú, azeitona-donordeste, ameixa roxa, murta, baga de feira, guapê, jambuí, azeitona-da-terra, entre outros nomes. Sua arvore é de grande porte e muito bem adaptada às condições 
brasileiras, apesar de ser originaria da Indonésia, China e Antilhas, é também cultivada em vários países, pois cresce muito bem em diferentes tipos de solo (Fetter et al, 2009).

A frutificação ocorre de janeiro a maio e os frutos são do tipo baga, assemelhando-se bastante com as azeitonas. Sua coloração, inicialmente branca, tornase vermelha e posteriormente preta, quando maduras. Sua semente fica envolvida por uma polpa carnosa e comestível, doce, mas adstringente, sendo agradável ao paladar. No Brasil, o fruto é geralmente consumido in natura, porém esta fruta pode ser processada na forma de compotas, licores, vinhos, vinagres, geléias, tortas, doces entre outros (Fetter et al, 2009)

A adstringência da poupa de brinco de viúva deve-se a presença de taninos, compostos fenólicos de alto peso molecular, que também estão presentes em frutas como caju e a banana verde. Contudo, a medida a que as frutas amadurecem, geralmente ocorre à redução da adstringência, que é atribuída à perda de solubilidade do tanino. Em pequenas proporções ou em combinação com outros componentes do alimento, a adstringência pode contribuir para um sabor desejável, como ocorre em vinhos elaborados com cultivares de uvas pigmentadas (Lago et al., 2006; Migliato et al, 2007)

Existem poucos trabalhos referentes à utilização deste fruto no processamento de alimentos, com destaque ao estudo realizado por Lago, Gomes e Silva (2006) na produção de geleia, com os demais voltados principalmente a combinação química e os efeitos benéficos do brinco de viúva como o potencial antibacteriano, diurético, antihipertensivo, antioxidante, bacteriológico e anti-inflamatório, sendo as suas propriedades medicinais diretamente ligadas ao alto conteúdo de compostos fenólicos, flavonoides e antocianinas. Dessa forma, a elaboração de produtos mais atrativos que o consumo da fruta in natura, que agregue valor de mercado e que mantenha os componentes benéficos presentes no fruto, pode ser considerada uma alternativa viável (Lago et al., 2006; Migliato et al, 2007)

Este trabalho teve como objetivo a produção do fermentado de brinco de viúva. Para tanto será utilizado o suco extraído do fruto, ainda maduro, e adicionado a este fermento biológico, Fermix. Este processo será acompanhado, juntamente com analises físico químicas, com o objetivo de avaliar o efeito de algumas variáveis como $\mathrm{pH}$, teor alcoólico, AR, ART. Após obter-se valores consideráveis, junto a normas exigidas pela União Brasileira de Vitivinicultura (UVIBRA), o vinho passou por uma análise sensorial para que fosse observada sua aceitação diante de provadores não treinados.

\section{METODOLOGIA}

\subsection{Local de Execução da Pesquisa}

A pesquisa foi realizada no laboratório de tecnologia de bebidas e alimentos (LTBA) do Centro de Tecnologia da UFAL. 


\subsection{Preparação do Suco}

Os frutos foram colhidos dentro da própria universidade (UFAL), de forma manual, e levados a laboratório onde foram avaliados e separados segundo a sua maturação, e seu estado de conservação. Após a separação, os frutos sofreram um processo de pré-lavagem, em água corrente, para a remoção de impurezas como folhas, terras e pedaços de galhos junto a eles. Após esse processo, foi preparado uma solução de $15 \mathrm{ppm}$ de cloro ativo $(15 \mathrm{ppm}=7,5 \mathrm{~mL}$ de cloro para $10 \mathrm{~mL}$ de água $)$ e adicionados junto ao fruto em um recipiente, e depois lavados novamente em água corrente. Os frutos então limpos foram levados a um liquidificador industrial, no qual foram processados e, a seguir, despejados em uma peneira pra a separação do suco do bagaço do fruto processado.

\subsection{Análise Físico-Química do Suco}

Foi utilizado como matéria prima o suco extraído do fruto brinco de viúva. A análise foi feita segundo os seguintes parâmetros em duplicata: A.R.T (Açúcares Redutores Totais) e A.R (açúcares redutores) ambos foram determinados com métodos de Eynon Lane, $\mathrm{pH}$ foi determinado baseado numa análise física, de leitura direta no pHmetro (AOAC, 1992) a acidez livre (IAL 310/IV) foi determinada com o emprego de uma solução titulada de uma base e a determinação do BRIX (Sólidos Solúveis em Solução) foi feito com o método refratométrico.

\subsection{Esterilização e Preparação do Mosto:}

Do suco extraído da fruta, foram separado 400mL, em 2 erlenmeyer, ambos formando o mosto. Os erlenmeyer então foram levados a um fogão convencional, para aquecimento, durante um período de $5 \mathrm{~min}$ depois levado a uma autoclave por $15 \mathrm{~min}$, a 1 atm, para a esterilização do mesmo, e posto a esfriar.

\subsection{Fermentação}

A levedura a ser inoculada, foi preparada com $2 \mathrm{~g}$ de glicose, $2 \mathrm{~g}$ de peptone e $1 \mathrm{~g}$ de extrato de levedura comum, contendo a levedura da espécie Saccharomyces cerevisiae, na forma de fermento comercial, e diluído, com água destilada, em um erlenmeyer de $100 \mathrm{~mL}$. Foi então inoculado a levedura em um dos erlenmeyer, homogeneizado e posto em uma incubadora por um período de $24 \mathrm{~h}$ a $32^{\circ} \mathrm{C}$. Depois desse período o mosto inoculado, foi então transferido para o segundo mosto, homogeneizado e levado novamente para a incubadora por um novo período de $24 \mathrm{~h}$ a $32^{\circ} \mathrm{C}$. Após esse período o mosto foi então posto em um tanque de plástico com capacidade de $15 \mathrm{~L}$ e verificou-se suas variáveis, como brix, $\mathrm{pH}$ e teor alcoólico durante um período de 11 dias. 


\subsection{Analise Físico-Química do Fermentado de Brinco de Viúva}

Foi feita a determinação do Brix, com o método refratométrico, a acidez livre (IAL 310/IV) foi determinada com o emprego de uma solução titulada de uma base, o $\mathrm{pH}$ foi determinado baseado numa analise física, de leitura direta no pHmetro e a determinação de etanol pelo o método espectrofotométrico. Essas análises foram sendo realizadas à medida que cada amostra foi sendo retirada a cada 24 horas.

\subsection{Análise Sensorial do Fermentado de Brinco de Viúva}

Após a produção do fermentado de brinco de viúva, foi feita uma análise sensorial, onde foi observado a sua aceitação diante de dez provadores não treinados. A análise foi feita, utilizando-se um vinho comercial suave, em comparativo com o fermentado de brinco de viúva onde foram analisados os seguintes parâmetros: aparência, odor, textura e sabor. Cada parâmetro foi então opinado segundo os critérios de: péssimo, ruim, regular, bom, excelente. Depois os provadores fizeram uma análise geral da amostra, segundo o seu consumo, avaliando os seguintes parâmetros: nunca beberia, beberia raramente, beberia ocasionalmente, beberia frequentemente, beberia sempre. Os resultados obtidos mostram que o fermentado produzido em laboratório teve uma aceitação adequada diante dos provadores.

\section{RESULTADOS E DISCUSSÕES}

Foi realizada uma análise sensorial comparando-se o vinho tradicional de uva suave, com o fermentado de brinco de viúva (vinho de brinco de viúva), onde foram analisados quatro itens específicos: aparência, odor, textura e sabor, referentes aos dois vinhos analisados. Cada item foi avaliado de maneira sucinta pelos provadores, e opinado segundo os critérios de péssimo, ruim, regular, bom. Foi utilizado um grupo de 10 pessoas para a realização da análise, com uma faixa de idade entre 19 - 30 anos, um grupo basicamente jovem, em que utilizaram de suas próprias percepções para a realização de análise qualitativa das amostras, como mostra as Tabelas 1 e 2:

Tabela 1 - Tabela com os dados da análise sensorial referente ao vinho de uva

\begin{tabular}{|c|c|c|c|c|}
\hline Critério & Aparência & Odor & Textura & Sabor \\
\hline Péssimo & 0 & 0 & 0 & 0 \\
\hline Ruim & 0 & 0 & 0 & 0 \\
\hline Regular & 2 & 3 & 2 & 4 \\
\hline Bom & 6 & 4 & 6 & 3 \\
\hline Excelente & 2 & 3 & 2 & 3 \\
\hline
\end{tabular}


Tabela 2 - Tabela com os dados da análise sensorial referente ao vinho de brinco de viúva

\begin{tabular}{|c|c|c|c|c|}
\hline Critério & Aparência & Odor & Textura & Sabor \\
\hline Péssimo & 1 & 0 & 0 & 1 \\
\hline Ruim & 1 & 2 & 1 & 1 \\
\hline Regular & 5 & 3 & 4 & 4 \\
\hline Bom & 2 & 3 & 5 & 2 \\
\hline Excelente & 1 & 1 & 0 & 2 \\
\hline
\end{tabular}

Foi ainda realizada uma análise geral em relação às duas amostras, onde foram julgados e opinados segundo os critérios mostrados na Tabela 3.

Tabela 3 - Análise geral para o consumo do vinho avaliado

\begin{tabular}{|c|c|c|}
\hline Critério & Vinho de Brinco de Viúva & Vinho de Uva \\
\hline Nunca beberia & 4 & 2 \\
\hline Beberia raramente & 2 & 3 \\
\hline Beberia ocasionalmente & 2 & 3 \\
\hline Beberia frequentemente & 1 & 1 \\
\hline Beberia sempre & 1 & 1 \\
\hline
\end{tabular}

As Figuras 1 e 2 que representam os gráficos de análise geral dos vinhos de brinco de viúva e vinho de uva, respectivamente.

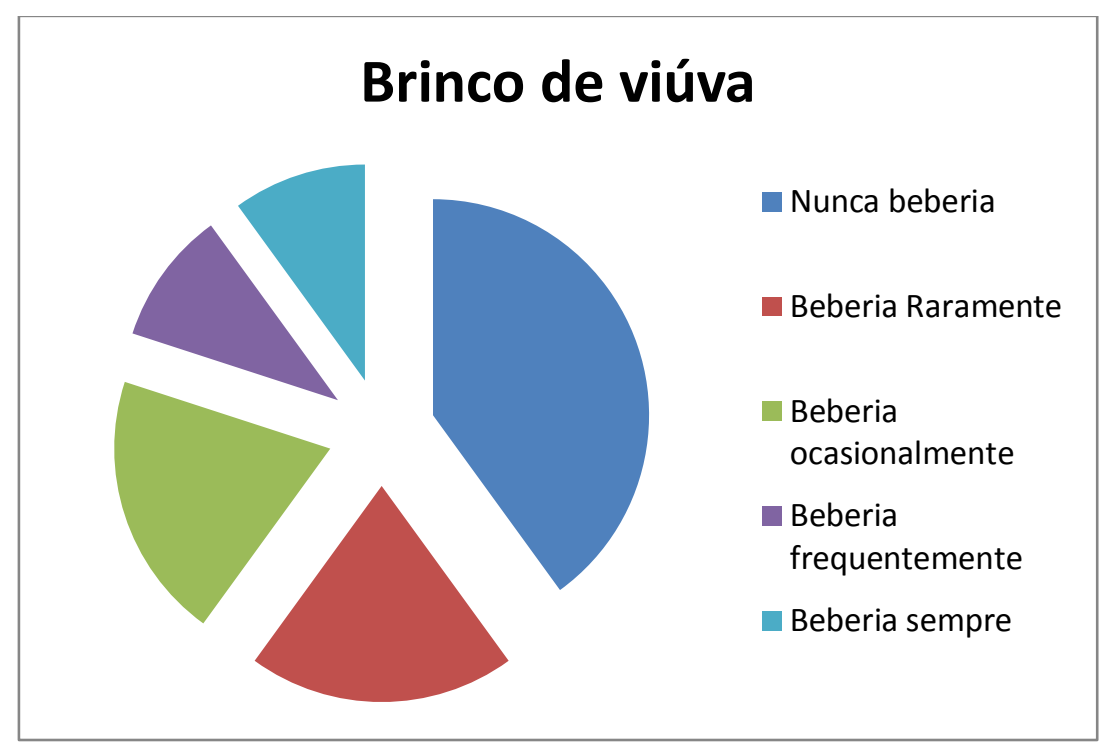


Figura 1 - Gráfico de análise geral do vinho de brinco de viúva.

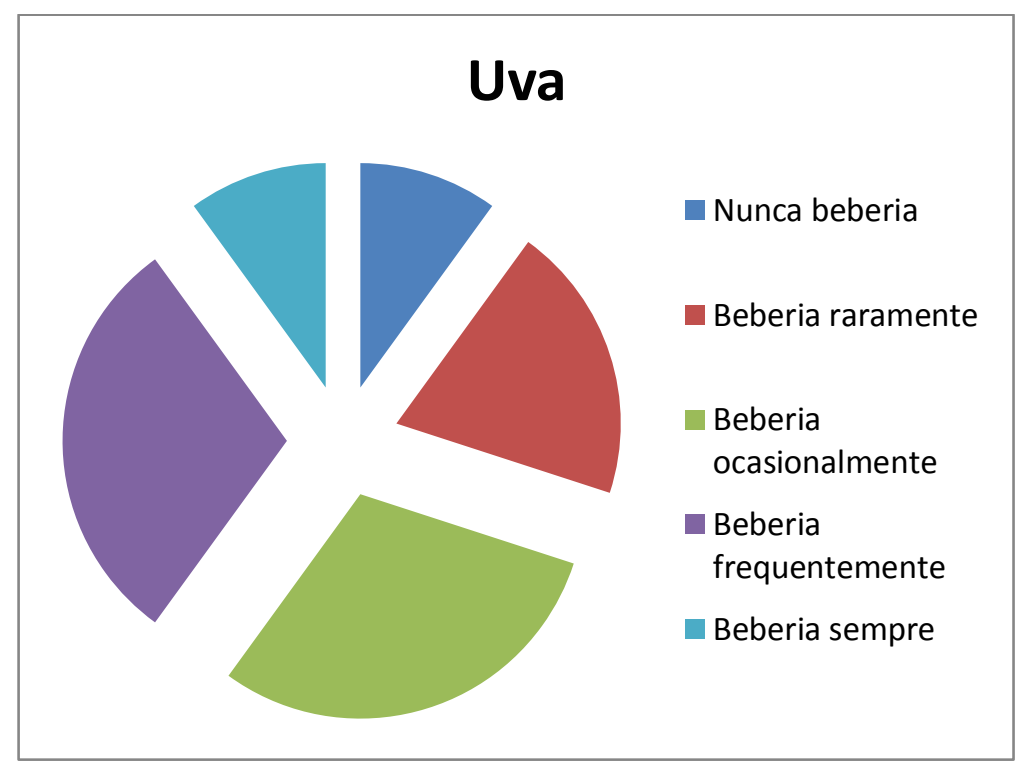

Figura 2 - Gráfico de análise geral do vinho de uva.

Esses resultados mostram que o fermentado de brinco de viúva teve uma aceitação, entre regular e bom como é mostrado na Tabela 2, se comparado ao vinho de uva comercial suave, principalmente nos critérios de textura e aparência, chegando a superar os valores do vinho de uva comercial. Já na Figura 1, para a análise geral, percebemos uma discordância dos provadores segundo os valores obtidos ainda na Tabela 2, pois para o critério nunca beberia, na Figura 1, observa-se que este foi o mais registrado e opinado pelos provadores, ainda que os critérios péssimo e ruim na Tabela 2 foram pouco opinados pelos provadores. Isso se deve aos provadores escolhidos não serem treinados para esta análise, pois estes foram escolhidos de maneira aleatória com o objetivo de se ter uma ideia, mas precisa da aceitação do fermentado de brinco de viúva para o publico em geral, mesmo que estes não sejam apreciadores de vinhos.

A Tabela 4 mostra os resultados finais da análise físico-química obtidos do fermentado de brinco de viúva.

Tabela 4 - Caracterização físico-química do fermentado de Brinco de viúva

\begin{tabular}{|c|c|}
\hline Variáveis do vinho de brinco de viúva & \multicolumn{1}{|}{} \\
\hline $\mathrm{pH}$ & 3,37 \\
\hline Vitamina C (g/L) & 2,07 \\
\hline AR $(\mathrm{g} / \mathrm{L})$ & 9,10 \\
\hline ART $(\mathrm{g} / \mathrm{L})$ & 9,56 \\
\hline Acidez $(\%)$ & 0,77 \\
\hline Teor alcoólico $\left({ }^{\circ} \mathrm{GL}\right)$ & 8,6 \\
\hline
\end{tabular}


Observa-se que os valores estão dentro dos padrões exigidos pela União Brasileira de Vitivinicultura, o que torna esse vinho apropriado para consumo e comercialização.

\section{CONCLUSÃO}

A partir de todas as análises realizadas, concluímos que o brinco de viúva torna-se uma alternativa em potencial para a produção de fermentados. Obtiveram-se valores consideráveis nas análises físico-químicas, apresentando valores de acordo com as normas exigidas pela legislação brasileira (UVIBRA). Os dados mostram que o fermentado foi bem aceito e não houve diferenças significativas com relação ao vinho comercializado (quinta do morgado, suave), para ambas as qualidades sensoriais, podendo ser uma nova fonte de investimento para pequenos produtores ou uma nova opção de mercado.

\section{REFERÊNCIA}

FETTER, M.R; VIZZOTTO, M. Jambolão: O Poderoso Antioxidante. Artigo de divulgação em mídia, Embrapa. 2009.

CNA - Confederação da Agricultura e Pecuária do Brasil. www.canaldoprodutor.com.br. 2014

LAGO, E. S; GOMES, E; SILVA, R. Produção de geleia de jambolão (Syzygium cumini Lamarck): processamento, parâmetros físico-químicos e avaliação sensorial. Centro de ciências e tecnologia de alimentos, Universidade Estadual Paulistas, 2006.

SOARES, M.N; HORNES, O.M; PERLIN, S.F; PEREIRA, D.T; SANTOS, M. Vinho de jambolão (Syzygium cumini) elaborado por duas formas de obtenção de poupa. Laboratório de Bromatologia, Instituto Federal Farroupilha - Campus São Vicente do Sul.

Migliato, K. F.; MOREIRA, R. R. D; MELlO, J. C. P. Controle da qualidade do fruto de Syzygium cumini (L.) Skeels. Faculdade de Ciências Farmacêuticas, Departamento de fármacos e medicamentos, Universidade Estadual Paulista 2006.

SANTOS , S.C; ALMEIDA, S.S; TOLEDO, A.L; SANTANA, J.C.C; SOUZA, R.R. Elaboração e analise sensorial do fermentado de acerola (Malpighia Punicifolia L.). Departamento de Engenharia Química, Universidade Federal de Sergipe, Brazilian Journal of Food technology, $5^{\circ}$ SIPAL, Março de 2005. 